\title{
The cost of stroke in a public hospital in Brazil: a one-year prospective study
}

\author{
Custo do AVC em um hospital público no Brasil: um estudo prospectivo de um ano \\ Juliana SAFANELLI', Luana Gabriela Dalla Rosa VIEIRA², Tainá de ARAUJO², Lidiana Fachinete Silva \\ MANCHOPE ${ }^{2}$, Maria Helena Ribeiro KUHLHOFF', Vivian NAGEL'1, Adriana Bastos CONFORTO ${ }^{3,4}$, Gisele \\ Sampaio SILVA ${ }^{5}$, Suleimy MAZIN7, Pedro Silva Corrêa de MAGALHÃES7, Norberto Luiz CABRAL'
}

\begin{abstract}
Low- and middle-income countries face tight health care budgets, not only new resources, but also costly therapeutic resources for treatment of ischemic stroke (IS). However, few prospective data about stroke costs including cerebral reperfusion from low- and middle-income countries are available. Objective: To measure the costs of stroke care in a public hospital in Joinville, Brazil. Methods: We prospectively assessed all medical and nonmedical costs of inpatients admitted with a diagnosis of any stroke or transient ischemic attack over one year, analyzed costs per type of stroke and treatment, length of stay (LOS) and compared hospital costs with government reimbursement. Results: We evaluated 274 patients. The total cost for the year was US $\$ 1,307,114$; the government reimbursed the hospital US $\$ 1,095,118$. We found a significant linear correlation between LOS and costs $(r=0.71)$. The median cost of 134 IS inpatients who did not undergo cerebral reperfusion (National Institutes of Health Stroke Scale [NIHSS] median = 3 ) was US $\$ 2,803$; for IS patients who underwent intravenous (IV) alteplase (NIHSS 10), the median was US\$5,099, and for IS patients who underwent IV plus an intra-arterial (IA) thrombectomy (NIHSS > 10), the median cost was US $\$ 10,997$. The median costs of a primary intracerebral hemorrhage, subarachnoid hemorrhage, and transient ischemic attack were US\$2,436, US\$8,031 and US $\$ 2,677$, respectively. Conclusions: Reperfusion treatments were two-to-four times more expensive than conservative treatment. A cost-effectiveness study of the IS treatment option is necessary.
\end{abstract}

Keywords: Stroke; hospital custs; cost of illness; socioeconomic factors.

\section{RESUMO}

Os países de baixa e media renda enfrentam orçamentos apertados na saúde, não somente devido aos novos recursos terapêuticos, mas relacionado ao custo oneroso do tratamento do acidente vascular cerebral. No entanto, poucos dados prospectivos sobre os custos do AVC, incluindo reperfusão cerebral de países de baixa e média renda estão disponíveis. Objetivo: Mensurar os custos do atendimento ao AVC em um hospital público. Métodos: Avaliamos prospectivamente todos os custos médicos e não médicos de pacientes internados com diagnóstico de acidente vascular cerebral ou AIT durante 1 ano, analisamos os custos por tipo de AVC e tratamento, tempo de permanência e comparamos os custos hospitalares com o reembolso governamental. Resultados: Foram avaliados 274 pacientes. O custo total em um ano foi de US\$1.307,114; o governo reembolsou o hospital no valor de US\$ 1.095.118. Encontramos uma correlação linear significativa entre LOS e custos $(r=0,71)$. A mediana do custo do AVCl em 134 pacientes que não sofreram reperfusão cerebral (National Institutes of Health Stroke Scale [NIHSS] mediana = 3) foi de US \$2.803; para pacientes submetidos a alteplase intravenosa (IV) (NIHSS 10), a mediana foi de US $\$ 5.099$ e para os pacientes submetidos a trombectomia intra-arterial (IA) (NIHSS > 10), o custo mediano foi de US\$10.997. A mediana do custo de uma hemorragia intracerebral primária, hemorragia subaracnóidea e AIT foram de US\$2.436, US\$8.031 e US\$2.677, respectivamente. Conclusões: Os tratamentos de reperfusão foram duas a quatro vezes mais caros do que o tratamento conservador. Estudo de custo-efetividade para o tratamento do AVC são necessários.

Palavras-chave: Acidente vascular cerebral; custos hospitalares; efeitos psicossocias da doença; fatores socioeconômicos.

\footnotetext{
'Universidade da Região de Joinville, Joinville Stroke Registry, Programa de Pós-Graduação em Saúde e Meio Ambiente, Joinville, SC, Brasil;

${ }^{2}$ Universidade da Região de Joinville, Programa de Pós-Graduação em Saúde e Meio Ambiente, Joinville, SC, Brasil;

${ }^{3}$ Universidade Federal de São Paulo, Divisão de Clínica Neurológica, São Paulo, SP, Brasil;

${ }^{4}$ Hospital Israelita Albert Einstein, São Paulo, SP, Brasil;

5Universidade de São Paulo, Hospital das Clínicas, São Paulo, SP, Brasil;

${ }^{6}$ Universidade de São Paulo de Ribeirão Preto, Hospital das Clínicas, Ribeirão Preto, SP, Brasil:

${ }^{7}$ Hospital Municipal São José, Unidade de AVC, Joinville, SC, Brasil.
}

Juliana Safanelli (iD) https://orcid.org/0000-0003-1924-8279; Luana Gabriela Dalla Rosa Vieira (iD https://orcid.org/0000-0003-4317-6914; Tainá de Araujo iD https://orcid.org/0000-0001-6558-5415; Maria Helena Ribeiro Kuhlhoff (iD https://orcid.org/0000-0003-1384-9444; Lidiana Fachinete Silva Manchope iD https:// orcid.org/0000-0003-1480-1223;Vivian Nagel (iD) https://orcid.org/0000-0002-3321-6110;Adriana Bastos Conforto (iD) https://orcid.org/0000-0001-7869-3490; Gisele Sampaio Silva (iD https://orcid.org/0000-0002-3247-3123; Suleimy Mazin (iD) https://orcid.org/0000-0001-6121-7295; Pedro Silva Corrêa Magalhães (iD) https://orcid.org/0000-0001-7297-1381; Norberto Luiz Cabral (iD) https://orcid.org/0000-0001-5829-9699

Correspondence: Juliana Safanelli; Universidade da Região de Joinville; Rua Paulo Malschitzki, 10;89219-710 Joinville SC, Brasil; E-mail:juliana.safanelli@gmail.com Conflict of interest: There is no conflict of interest to declare.

Support: This study was supported by the National Council for Scientific and Technological Development, CNPq Grant 402396/2013-8.

Received 21 September 2018; Received in final form 07 January 2019; Accepted 18 February 2019. 
Epidemiological data predict a worldwide increase in the cost of strokes ${ }^{1,2}$. One of the main reasons is the increase in the prevalence that will result from falling mortality rates ${ }^{1}$. Data are scarce about stroke costs in low- and middle-income countries, but in high-income countries, an average of $3 \%$ of the government health care budget is spent on stroke costs ${ }^{3}$. This amount includes hospital costs and indirect costs due to productivity losses and premature mortality ${ }^{4}$. Hospital costs have been estimated to represent anywhere between $28 \%$ and $83 \%$ of the total cost of strokes, the percentage being largely determined by the calculation method used for social costs ${ }^{4,5}$.

In Brazil, the state-run health care system is universal. Three quarters of the population use it exclusively and one quarter uses both public and private health services ${ }^{6}$. In 2013, 12.1 million people were hospitalized in Brazil, and eight million benefited from the public health system ${ }^{7}$. Stroke units and cerebral reperfusion options have become national public health priorities ${ }^{8}$, but the Brazilian Ministry of Health does not have an up-to-date information system, so cost data are missing. In São Paulo, a retrospective study published in 2009 estimated in-hospital costs to be US\$4,101 for primary intracerebral hemorrhage (PIH) and US\$1,902 for ischemic stroke (IS $)^{9}$. We aimed to measure public in-hospital costs for IS with and without cerebral reperfusion, PIH, subarachnoid hemorrhage (SAH), and transient ischemic attack (TIA) in Joinville, Brazil.

\section{METHODS}

\section{Study population}

The Joinville Stroke Registry is an ongoing populationbased study that has been running since 2005. Its methods have been extensively published elsewhere ${ }^{10}$. The cost of illness was extracted from the Hospital Municipal São José, a reference public hospital that serves 1.2 million people in the northeastern region of the state of Santa Catarina. In 2017, Joinville had a score of 0.809 in the human development index (ranking $21^{\text {st }}$ among 5,570 Brazilian cities).

\section{Official payment data}

To define the amount of government payments, the Unified Health System (SUS) uses a unified table of procedures called System of Management of the Table of Procedures and Medications ${ }^{11}$. The SUS refunds US\$611 for IS that requires a hospital stay of up to seven days. If the patient undergoes intravenous thrombolysis, the refund is US\$1,219, and unfortunately the intra arterial thrombectomy is not yet reimbursed by the Brazilian Health System ${ }^{11,12}$. We used the criteria for health costs management from the Ministry of Health for our hospital cost definitions ${ }^{12}$.

\section{Pilot study}

In the absence of standard methodology in computing the direct costs of stroke in a public hospital in Brazil, we conducted a pilot study in August 2016. For each patient, the principal investigator verified all checklist items daily during the hospital stay. Other data such as demographics, socioeconomic information, stroke scales (clinical and functional), and clinical outcomes were extracted from the Joinville Stroke Registry ${ }^{10,13}$. In this study phase, we compared all final bills for each patient with account department data.

\section{Method and period of data collection}

This was a cost-of-illness and one-year prevalence-based study $^{14}$. We prospectively extracted the data from September 1, 2016 to August 30, 2017. We included subjects with IS, PIH, SAH and TIA, first-ever or not, aged $\geq 18$ years. We excluded patients with incomplete medical records and those who were transferred from another hospital. The IS severity was stratified according to the National Institutes of Health Stroke Scale (NIHSS): 1-3 (minor); 4-10 (moderate) and > 10 (severe) $)^{15}$.

\section{Daily hospital cost}

The daily hospital cost was a composition of medical and nonmedical costs. Direct medical costs included all items that encompass patient care-such as medical, nursing, and rehabilitation attendance and procedures; diagnosis workups; all items with medical and nursing prescriptions; diets for patients and companions; and items for personal hygiene. Table 1 shows the daily hospital composition among health care professionals to obtain the final cost per patient per day. The costs of diagnosis work-up included the unit price of each biochemical and radiological tests. The unit cost of each biochemical examination was the sum of the fraction of all personal labour costs and material costs for blood extraction and analysis. As cranial tomography and magnetic resonance imaging services are outsourced, the values were extracted from the System of Management of the Table of Procedures, Medications and Office of Personal Management of SUS (SIGTAP) ${ }^{11}$.

The unit costs of electrocardiograms, X-rays, video fluoroscopic swallowing studies, and carotid ultrasound and transcranial Doppler investigations included the material costs of each examination plus the labour-hour costs of all professionals of the radiology sector. Daily medical prescription items included all drugs, intravenous fluids and medicinal gases, whose costs were obtained in the purchasing sector according to the Brasíndice 2016 table. ${ }^{16}$ The nonmedical components of the daily hospital cost were electrical power consumption $(\mathrm{kw})$, water $\left(\mathrm{m}^{3}\right)$, garbage and laundry collection, and kitchen, pharmacy, sanitation, and cleaning personnel.

\section{Administrative fees}

We included the costs of administrative assistants. All wages, labour and employer expenses, and costs for benefits 
Table 1. Daily hospital cost composition for professionals.

\begin{tabular}{|c|c|}
\hline \multicolumn{2}{|r|}{ Professional fee composition } \\
\hline Nurse and rehabilitation personnel* & $\begin{array}{l}\text { (cost per hour } \times \text { number of hours per day on } \\
\text { call) / (number of patients per sector) }=\text { daily } \\
\text { cost per patient }\end{array}$ \\
\hline Neurologist, neurosurgeon & $\begin{array}{c}\text { (cost per hour } x \text { number of hours per patient) } / \text { (number of patients per area) }=\text { cost per patient } \\
\text { per day }\end{array}$ \\
\hline Any on-call physicians & $\begin{array}{c}{[(\text { wage per hour+ social and labour benefits })+(1 / 3 \text { of wage per hour } x \text { number of hours on }} \\
\text { procedure or attendance })=\text { daily cost per patient }\end{array}$ \\
\hline
\end{tabular}

*The nurse wages vary between hospital areas, according to patient severity and dependence level. Rehabilitation team: physiotherapist, speech therapist, occupational therapist, psychologist and social worker.

Table 2. Total in-hospital costs and daily costs by stroke type and TIA.

\begin{tabular}{lccccc}
\hline Variable & IS $(n=196)$ & PIH $(n=31)$ & SAH $(n=13)$ & TIA $(n=34)$ & $p$-value \\
\hline Total cost (median, IQR) & $3,320(2,361-5,873)$ & $2,436(1,351-4,524)$ & $8,031(6,233-9,076)$ & $2,677(2,157-3,483)$ & $<0.0001$ \\
Total cost (mean, SD) & $5,020(3,065)$ & $3,741(2,673)$ & $8,508(2,135)$ & $2,833(1,140)$ \\
Daily cost (median, IQR) & $350(157-392)$ & $221(123-412)$ & $567(405-605)$ & $243(196-316)$ & $<0.0001$ \\
Daily cost (mean, SD) & $256(204)$ & $226(242)$ & $535(142)$ & $258(104)$ & $<0.0001$ \\
\hline
\end{tabular}

SD: standard deviation; IQR: interquartile range; values in United States dollars (US\$); All values were adjusted to gross domestic product deflator index and purchasing power parity ${ }^{18}$.

such as food and transportation vouchers were added together, and the total was divided by the annual average of attendance. The consumption per patient per day were calculated based on absorption and apportionment costing methods ${ }^{17}$.

\section{Statistical analysis}

We evaluated the differences among patient subgroups by using a $\chi^{2}$ test, $t$ test, or Mann-Whitney $U$ test as appropriate. All tests were two tailed. We converted the cost data to the 2013 currency values by using a web-based tool (CCEMG-EPPI-Centre cost converter) ${ }^{14,18}$. First, it converted the cost into Brazil's current cost per year by using the gross domestic product (GDP) deflator index, and then it converted this cost into US dollars (US\$) (for the year 2016) by using conversion rates based on purchasing power parity (PPP) for the GDP (Brazil's real PPP value in 2016 was $0.49)^{18}$. For comparison, we also converted the original costs of other studies to costs for the year 2016. We ran the tests in Statistical Analysis System software, version 9.2, with PROC GENMOD (SAS Institute, Inc., Cary, NC). The study was approved by the ethics in research committees of the hospital and university involved.

\section{RESULTS}

We calculated the costs of 274 patients. From those, $71 \%$ $(196 / 274)$ had IS, $12 \%(34 / 274)$ had TIAs, $11 \%(31 / 274)$ had PIHs, and 6\% (13/274) had SAHs. The mean age was 60 years old (SD \pm 27$)$. The median NIHSS was 6 for IS patients (IQR: 6-12), 7 (IQR: 4-17) for PIH patients, and 8 (IQR: 8-18) for SAH patients. Among the 196 IS patients, 32\% (63) had mild strokes (NIHSS: 1-3), 37\% (73) had moderate strokes (NIHSS:
4-10), and 31\% (60) had severe strokes (NIHSS: > 10). The case-fatality at 30 days was $14 \%$ (28/196) for IS patients, $25 \%$ (8/31) for PIH patients and 53\% (7/13) for SAH patients. The length of stay (LOS) was 13 days (SD \pm 12 ) for IS patients, 12 days $(\mathrm{SD} \pm 13)$ for $\mathrm{PIH}$ patients, 14 days $(\mathrm{SD} \pm 6)$ for $\mathrm{SAH}$ patients, and 11 days (SD \pm 5 ) for TIA patients.

The overall cost for all 247 stroke patients who were admitted during one year was US\$1,307,114 and the SUS reimbursed US\$1,095,118. Table 2 shows the total costs and daily costs by stroke type.

The total costs ranged significantly from US\$2,163 for IS patients to US\$8,160 for SAH patients ( $p<0.001)$. Among 31 patients with $\mathrm{PIH}$, only $6 \%(2 / 31)$ underwent surgery, and the median cost was US\$17,709. The cost for PIH patients who did not undergo surgery was US\$2,653 ( $\mathrm{p}<0.001$ ). Among 13 patients with SAH, 53\% (7/13) underwent surgical procedures at a cost of US\$8,703 and US\$6,885 for patients who did not undergo surgery. The median and mean costs for seven patients with cardioembolic IS due to atrial fibrillation were US\$6,386 (IQR: 4,003-10,589) and US\$9,505 (SD \pm 7,612), respectively. As expected, the mean cost of hospitalization increased with LOS. For IS patients, the seven-day cost was US $\$ 2,697$, increasing to US\$3,821 for 14 days and to US $\$ 7,517$ when the LOS was longer than 15 days. Figure 1 shows the significant linear correlation between LOS and cost for IS patients. The IS costs ranged significantly according clinical severity (Figure 2). Whatever the stroke type or TIA, costs increased significantly per LOS (Table 3 ).

Figure 3 shows the median costs of TIAs, PIHs, SAHs, and ISs with and without cerebral reperfusion.

As expected, the cost of IA thrombectomy was three to four times higher than that of intravenous (IV) reperfusion $(\mathrm{p}<0.001)$. There was no statistical difference in age between 
IS patients treated with or without cerebral reperfusion $(\mathrm{p}=0.72$; Table 4$)$.

The proportions of costs, including daily hospital costs, drug costs, costs for medical procedures, costs for diagnosis work-ups, costs for medical gases, and diet and administration fees are available in Figure 4. Table 5 shows the unit costs of each item and the average cost per stroke type over the year. Daily hospital costs in the emergency, intensive care, and stroke unit sectors made up 53\% of all the final bills (US\$695,991 of US\$1,307,114). The second most expensive item was the category of medical procedures. The proportion of costs for diagnostic work-up ranged from $15 \%$ for TIAs to $4 \%$ to SAH patients. These procedures made up 16\% of the total bill (US\$211,366 of US\$1,307,114). The intra-arterial thrombectomy, which were performed in

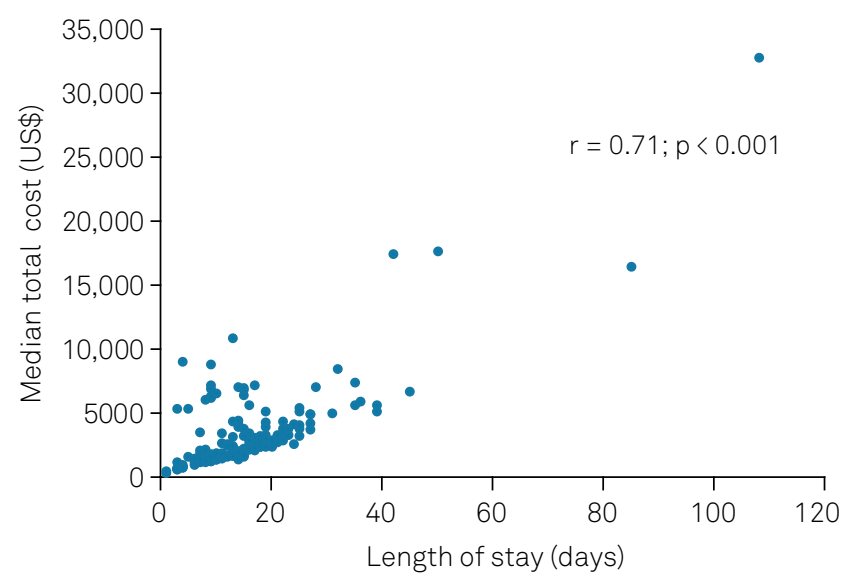

Figure 1. Linear regression between length of stay and IS costs.

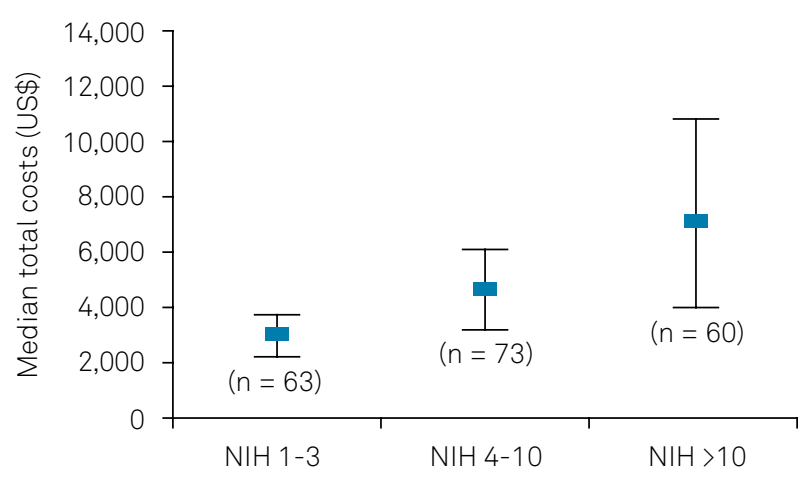

Figure 2. Ischemic stroke cost per clinical severity.
$7 \%$ of all patients $(21 / 274)$, made up $12 \%$ (US\$158,331 of US\$1,307,114) of the total bill.

\section{DISCUSSION}

In a public hospital using a prospective micro-costing methodology, the overall in-hospital cost of 274 strokes over one year was approximately US\$1.3 million; the government reimbursed approximately $\$ 1.1$ million. The median stroke cost per patient was US $\$ 7,470$. Therefore, the Brazilian Health System stroke underfunding is a tremendous hurdle to overcome ${ }^{19}$. Thrombolysis and thrombectomy have been performed at the hospital since $2005^{20}$. We found that the inhospital cost of an IS with cerebral reperfusion was significantly more expensive than conservative treatment, reaching, for those who underwent combined reperfusion, four times higher costs.

The overall per-day costs were approximately US $\$ 400$ and, regardless of stroke type, all costs increased with LOS and clinical severity. Our mean LOS was around two weeks for major strokes and around 11 days for a TIA. We compared these data with those of other studies from developing countries and found that our IS LOS (13 days) was shorter than that of patients in China (average of 20 days) ${ }^{21}$; similar to that of patients in India ${ }^{22}$, Brazil ${ }^{9}$, and Turkey ${ }^{23}$; and higher than that of patients in Thailand (eight days) ${ }^{24}$, Malaysia (six days $)^{25}$, and Pakistan ( five days) ${ }^{26}$.

Many pitfalls exist in analyses of stroke costs in countries at different times ${ }^{13,27}$. In order to compare our findings with those regarding the costs of other hospitals, we adjusted the costs of the original studies to the GDP deflator index and PPP in 2016. Therefore, our median IS cost of US $\$ 2,803$ (without cerebral reperfusion) was higher than the costs in Thailand (US $\$ 1,800$ and Turkey (US\$1,406) ) $^{23,24}$ but lower than the cost in Argentina (US\$3,778) 2 $^{28}$. In our IS sample, $31 \%$ of patients underwent cerebral reperfusion. Our median cost for IS IV lysis was US\$5,099, and the median cost for IV+IA lysis was US\$10,997. These amounts were much lower than the amount in the United States. For instance, the median hospital cost for IS patients who received IV thrombolysis from 2001 to 2008 was US\$63,472 in the United States and US\$14,102 in Brazil (IQR: 9,987-20,819) ${ }^{29}$. Studies in the United States have reported costs even higher than this median cost. For IV lysis, costs in the United States ${ }^{30}$ ranged

Table 3. Hospital costs by stroke type and LOS.

\begin{tabular}{|c|c|c|c|c|c|}
\hline Title & IS $(n=196)$ & $\mathrm{PIH}(n=31)$ & $\mathrm{SAH}(n=13)$ & TIA $(p=34)$ & $p$-value \\
\hline 1 week US\$ & $1,194(1,088-1,705)$ & $2,283(1,239-4,023)$ & - & $2,532(1,727-3,563)$ & 0.041 \\
\hline 2 weeks US\$ & $2,773(2,291-3,720)$ & $2,424(1,334-4,454)$ & $7,871(6,469-9,449)$ & $2,419(2,182-3,429)$ & 0.018 \\
\hline$>2$ weeks US $\$$ & $5,231(4,214-7,893)$ & $2,507(2,066-4,869)$ & $9,956(8,120-10,885)$ & $2.823(2,258-3,816)$ & 0.003 \\
\hline LOS (days) & $13(12)$ & $12(13)$ & $14(6)$ & $11(5)$ & 0.75 \\
\hline
\end{tabular}

LOS: length of stay values in means (SD); cost values are adjusted median cost (IQR); United States dollars (US\$). 


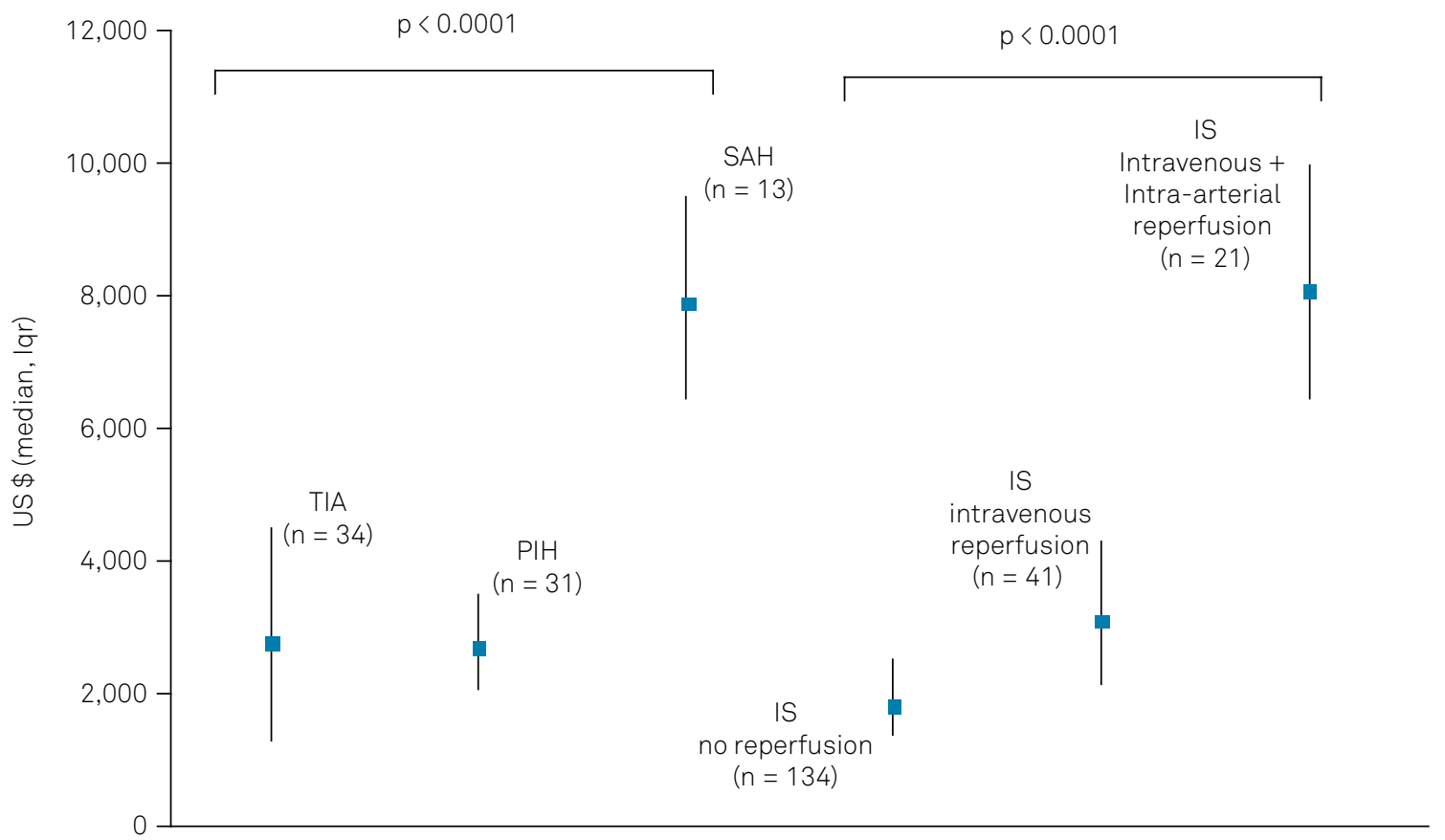

TIA: transient ischemic attack; $\mathrm{PIH}$ : primary intracerebral hemorrhage; $\mathrm{SAH}$ : subarachnoid hemorrhage; IS: ischemic stroeke.

Figure 3. Costs of stroke in a public hospital, Joinville, Brazil.

Table 4. IS treatment costs, clinical severity, LOS, and 30-day outcomes.

\begin{tabular}{|c|c|c|c|c|}
\hline Title & No reperfusion $(n=134)$ & IV r-tPA $(n=41)$ & $\begin{array}{c}\text { IV r-tPA + IA } \\
\text { thrombectomy }(n=21)\end{array}$ & $\mathrm{p}$-value \\
\hline Age (SD) & $62(13)$ & $66(14)$ & $66(12)$ & 0.72 \\
\hline NIHSS (median, IQR) & $6(2-8)$ & $9(6-12)$ & $19(13-22)$ & $<0.0001$ \\
\hline \multicolumn{5}{|l|}{ Total cost } \\
\hline US\$ (median, IQR) & $2,803(2,189-3,974)$ & $5,099(3,304-6,802)$ & $10,997(10,005-16,955)$ & $<0.0001$ \\
\hline (mean, SD) & $2,866(1,246)$ & $4,978(2,527)$ & $13,510(6,711)$ & $<0.0001$ \\
\hline \multicolumn{5}{|l|}{ Day cost } \\
\hline US\$ (median, IQR) & $255(199-361)$ & $364(236-485)$ & $846(769-1,304)$ & $<0.0001$ \\
\hline (mean, SD) & $261(113)$ & $356(181)$ & $1,039(516)$ & $<0.0001$ \\
\hline LOS (mean, SD) & $11(5)$ & $14(14)$ & $13(12)$ & 0.11 \\
\hline
\end{tabular}

from US $\$ 24,817$ to US $\$ 33,810$, and for IV+IA lysis, the costs in the United States ranged from US $\$ 39,825$ to US\$40,74330.

Our cost for PIH patients who underwent surgery (US\$17,709) was higher than the cost reported in 2009 in São Paulo 9 (US\$11,455). However, in both studies, the samples were very small (2/31 in Joinville and 6/45 in São Paulo). A recent cohort study ${ }^{31}$, conducted in Canada on the median cost for 987 patients with PIH, reported that the median cost ranged from US $\$ 4,685(2,761-7,196)$ to US $\$ 8,867(3,867-13,612)$.

Subarachnoid hemorrhages were the most expensive among all the stroke types; we found that the median cost for them was US\$8,031. Few studies focused on inpatient costs of aneurysmal $\mathrm{SAHs}^{31}$. Our SAH in-hospital costs were lower than those in Germany ${ }^{32}$ (US\$13,980), the
United States $^{33}$ (US\$41,905), Singapore ${ }^{34}$ (US\$13,673), and Australia $^{35}$ (US\$25,880). All of these were lower than in the United States ${ }^{36}$, where the median costs of hospitalization were US\$79, 916 for clipped patients and US $\$ 56,910$ for coiled patients.

Our TIA median cost was US $\$ 2677$. This amount is lower than the median cost of US\$3,173 in the Netherlands. In a retrospective study ${ }^{37}$ with 21, 653 TIA patients, the mean LOS was five days, which is much lower than our LOS of 11 days. In this Dutch study, the cost difference between inpatient ISs (US\$6,845) and inpatient TIAs (US\$3,173) was caused by a shorter LOS for TIA patients (3.6 days vs 8.8 days for IS patients), which could have been expected, given the lower severity and shorter symptom duration of TIAs ${ }^{37}$. The waiting 


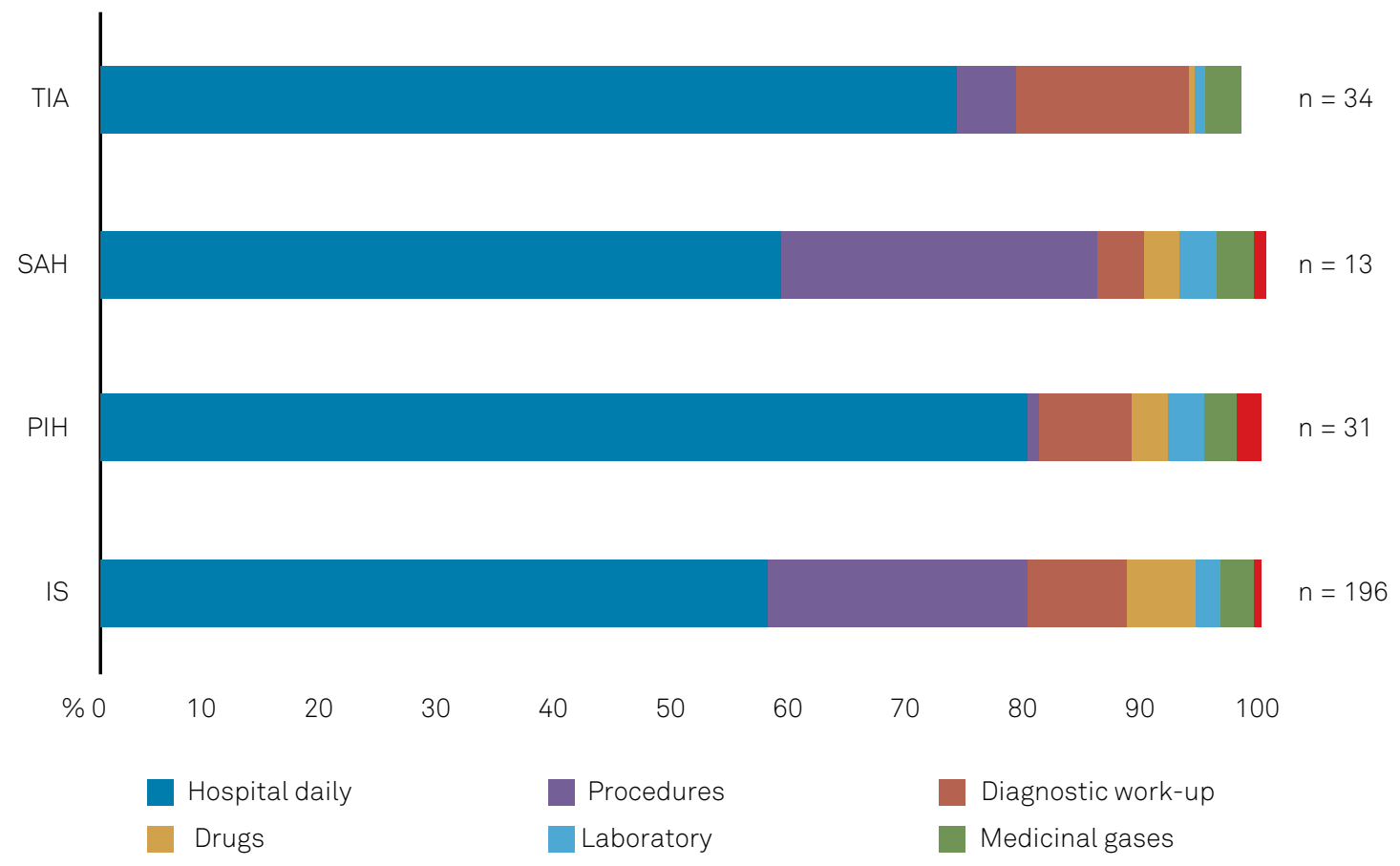

TIA: transient ischemic attack; SAH: subarachnoid hemorrhage; PIH: primary intracerebral hemorrhage.

Figure 4. Composition of hospital costs by type of stroke.

Table 5. Unit costs and average composition of costs by stroke type.

\begin{tabular}{|c|c|c|c|c|c|}
\hline Cost item & Unit costs & IS $(n=196)$ & $\mathrm{PIH}(n=31)$ & $\mathrm{SAH}(n=13)$ & TIA $(n=34)$ \\
\hline \multicolumn{6}{|l|}{ Hospital stay } \\
\hline Emergency department & 184.91 & $116,879.21$ & $45,857.68$ & $2,043.83$ & $34,075.48$ \\
\hline Intensive care days & 304.62 & - & - & $29,800.30$ & - \\
\hline Stroke unit & 153.51 & $371,055.52$ & $21,532.32$ & $33,281.03$ & $23,369.42$ \\
\hline \multicolumn{6}{|l|}{ Visits } \\
\hline Medical & 15.32 & $46,032.64$ & $5,699.04$ & $7,589.08$ & $3,646.16$ \\
\hline On-call & 28.19 & $29,575.72$ & $3,495.56$ & $4,366.47$ & $9,560.80$ \\
\hline Medical procedures & $728.46^{\star}$ & $11,655.36$ & $5,832.42$ & $30,587.34$ & $4,961.50^{\dagger}$ \\
\hline Thrombectomy & $6,884.12$ & $158,331.64$ & - & - & - \\
\hline Physiotherapy & 9.09 & $24,253.12$ & $2,254.32$ & 890.85 & 545.40 \\
\hline Occupational therapy & 9.09 & 5863.28 & 163.62 & 218.17 & 309.06 \\
\hline Speech therapy & 9.09 & $10,808.20$ & $2,817.90$ & 827.19 & 309.06 \\
\hline Psychotherapy & 7.67 & $3,006.64$ & 713.31 & 498.55 &.. \\
\hline \multicolumn{6}{|l|}{ Diagnostic and imaging tests } \\
\hline CT (brain) & 47.62 & $24,667.04$ & $1,952.42$ & $1,238.12$ & $2,127.08$ \\
\hline Carotid ultrasound & 58.31 & $11,428.76$ & - & - & $1,982.54$ \\
\hline ECG & 14.87 & $2,914.52$ & 490.71 & 193.31 & 505.58 \\
\hline X-ray (thorax) & 30.13 & $11,810.96$ & $2,802.09$ & 738.38 & $1,024.42$ \\
\hline MRI (brain) & 197.03 & $13,411.00$ & 394.06 & 197.03 & $5,713.96$ \\
\hline MRA, CTA & 181.82 & $8,588.30$ & - & 330.20 & $2,181.84$ \\
\hline Echocardiogram TT & 25.65 & $6,283.20$ & 153.90 & - & $1,297.10$ \\
\hline Laboratory investigations $^{\ddagger}$ & 75.56 & $15,809.76$ & $3,342.36$ & $3,691.75$ & $2,774.80$ \\
\hline Drugs & 6.08 & $14,297.16$ & 974.11 & $16,522.54$ & 238.41 \\
\hline r-tPA-alteplase & 408.11 & $35,097.90$ & - & - & - \\
\hline Antibiotics & 12.22 & $10,597.43$ & $2,737.28$ & $1,510.80$ & - \\
\hline Medicinal gases & 21.82 & $5,923.26$ & $2,285.23$ & $1,710.65$ & - \\
\hline Administrative fees & 60.35 & $11,828.60$ & $1,870.85$ & 784.55 & $2,051.90$ \\
\hline Sub-totals & & $976,069.42$ & $108,382.59$ & $124,979.31$ & $97,685.01$ \\
\hline Total & & & & & $1,307,114.10$ \\
\hline
\end{tabular}


time for diagnosis work-ups was the main reason for the high LOS of our TIA patients ${ }^{38}$.

Our study has some limitations. The first and most important limitation is the absence of a structured cost centre at the Hospital Municipal São José. Therefore, extracting from distinct search methods for hospital $\operatorname{costs}^{39}$, we built a new method in a public-hospital context. Although all the results during the pilot phase were matched with the financial-hospital sector, our comprehensive methods have not yet been validated. Still, no gold standard method exists for the evaluation of the costs of strokes. Second, our samples of patients with IS who underwent IA lysis, patients with PIH, and patients who underwent surgery were very small. Third, this was a singlecentre study and, therefore, the potential for extrapolation of data to the national level is limited. The study's strengths include a prospective design covering all daily medical and nonmedical items over one year in a public setting.

In conclusion, stroke is a costly disease. For SAH and IS patients, mechanical thrombectomy and greater lengths of stay were associated with greater costs, as described in studies performed in other countries. Further studies evaluating the cost-effectiveness for IS cerebral reperfusion in developing countries are sorely needed. The Brazilian Health System is underfunding the stroke costs in our setting.

\section{References}

1. Feigin VL, Forouzanfar MH, Krishnamurthi R, Mensah GA, Connor M, Bennett DA, et al. Global and regional burden of stroke during 1990-2010: findings from the Global Burden of Disease Study 2010. Lancet. 2014 Jan;383(9913):245-54. https://doi.org/10.1016/S0140-6736(13)61953-4

2. Heidenreich PA, Trogdon JG, Khavjou OA, Butler J, Dracup K, Ezekowitz MD, et al. Forecasting the future of cardiovascular disease in the United States: a policy statement from the American Heart Association. Circulation. 2011 Mar;123(8):933-44. https://doi.org/10.1161/CIR.0b013e31820a55f5

3. Goeree R, Blackhouse G, Petrovic R, Salama S. Cost of stroke in Canada: a 1-year prospective study. J Med Econ. 2005;8(1-4):147-67. https://doi.org/10.3111/200508147167

4. Dewey HM, Thrift AG, Mihalopoulos C, Carter R, Macdonell RA, McNeil JJ, et al. Cost of stroke in Australia from a societal perspective: results from the North East Melbourne Stroke Incidence Study (NEMESIS). Stroke. 2001 Oct;32(10):2409-16. https://doi.org/10.1161/hs1001.097222

5. Bergman L, van der Meulen JH, Limburg M, Habbema JD. Costs of medical care after first-ever stroke in The Netherlands. Stroke. 1995 Oct;26(10):1830-6. https://doi.org/10.1161/01.STR.26.10.1830

6. Paim J, Travassos C, Almeida C, Bahia L, Macinko J. The Brazilian health system: history, advances, and challenges. Lancet. 2011 May;377(9779):1778-97. https://doi.org/10.1016/S0140-6736(11)60054-8

7. Ministério da Saúde (BR). Datasus. Serviços/SIHSUS.2017. Brasília, DF:[cited 2018 Feb 25]. Available from: http://www2.datasus.gov.br/ DATASUS/index.php?area $=0202 \&$ id $=11633$

8. Ministério da Saúde (BR). Manual de rotinas para atenção ao AVC .Brasília, DF: Ministério da Saúde; 2013 [cited 2018 Feb 25]. Available from: http://bvsms.saude.gov.br/bvs/publicacoes/manual_ rotinas_para_atencao_avc.pdf

9. Christensen MC, Valiente R, Sampaio Silva G, Lee WC, Dutcher S, Guimarães Rocha MS, et al. Acute treatment costs of stroke in Brazil. Neuroepidemiology. 2009;32(2):142-9. https://doi.org/10.1159/000184747

10. Cabral NL, Freire AT, Conforto AB, Dos Santos N, Reis FI, Nagel $V$, et al. Increase of stroke incidence in young adults in a middle-income country: a 10-year population-based study. Stroke. 2017 Nov;48(11):2925-30. https://doi.org/10.1161/STROKEAHA.117.018531

11. Ministério da Saúde (BR). Sistema de Gerenciamento da Tabela de Procedimentos, Medicamentos e OPM do SUS. Tabela unificada. Brasília, DF: Ministério da Saúde, 2010; [cited 2018 Feb 25]. Available from: http://sigtap.datasus.gov.br/tabela-unificada/app/sec/inicio. jsp?first $=10$
12. Ministério da Saúde (BR). Introdução à gestão de custos em saúde Brasília, DF: Ministério da Saúde; 2013 [cited 2018 Feb 25]. Available from:.http://bvsms.saude.gov.br/bvs/publicacoes/introducao_ gestao_custos_saude.pdf

13. Associação Brasileira de Empresas de Pesquisa - ABEP. Critério Brasil 2018. São Paulo: Associação Brasileira de Empresas de Pesquisa; 2018 [cited 2018 Feb 25]. Available from: http://www.abep. org/criterio-brasil

14. Evers SM, Struijs JN, Ament AJ, Genugten ML, Jager $\mathrm{JH}$, Bos GA. International comparison of stroke cost studies. Stroke. 2004 May;35(5):1209-15. https://doi.org/10.1161/01.STR.0000125860.48180.48

15. Brott T, Adams HP Jr, Olinger CP, Marler JR, Barsan WG, Biller J, et al. Measurements of acute cerebral infarction: a clinical examination scale. Stroke. $1989 \mathrm{Jul} ; 20(7): 864-70$. https://doi.org/10.1161/01.STR.20.7.864

16. Brasíndice.Troca de informações em saúde suplementar. 2010.[cited 2018 Feb 25]. Available from: https//www.brasindice.com.br/.

17. Laudicella M, Olsen KR, Street A. Examining cost variation across hospital departments - a two-stage multi-level approach using patient-level data. Soc Sci Med. 2010 Nov;71(10):1872-81. https://doi.org/10.1016/j.socscimed.2010.06.049

18. Shemilt I, Thomas J, Morciano M. A web-based tool for adjusting costs to a specific target currency and price year. Evid Policy. 2010;6(1):51-9. https://doi.org/10.1332/174426410X482999

19. Seta $\mathrm{MH}$, Oliveira CV, Pepe VL. Health protection in Brazil: the National Sanitary Surveillance System. Cien Saude Colet. 2017 Oct;22(10):3225-34. https://doi.org/10.1590/1413-812320172210.16672017

20. Cabral NL, Conforto A, Magalhaes PS, Longo AL, Moro $\mathrm{CH}$, Appel $\mathrm{H}$, et al. Intravenous rtPA versus mechanical thrombectomy in acute ischemic stroke: A historical cohort in Joinville, Brazil. eNeurologicalSci. 2016 Apr;5:1-6. https://doi.org/10.1016/j.ensci.2016.04.002

21. Wei JW, Heeley EL, Jan S, Huang Y, Huang Q, Wang JG, et al.; ChinaQUEST Investigators. Variations and determinants of hospital costs for acute stroke in China. PLoS One. 2010 Sep;5(9):1-9. https://doi.org/10.1371/journal.pone.0013041

22. Kwatra G, Kaur P, Toor G, Badyal DK, Kaur R, Singh Y, et al. Cost of stroke from a tertiary center in northwest India. Neurol India. 2013 Nov-Dec;61(6):627-32. https://doi.org/10.4103/0028-3886.125270

23. Asil T, Celik Y, Sut N, Celik AD, Balci K, Yilmaz A, et al. Cost of acute ischemic and hemorrhagic stroke in Turkey. Clin Neurol Neurosurg. 2011 Feb;113(2):111-4. https://doi.org/10.1016/j.clineuro.2010.09.014 
24. Khiaocharoen O, Pannarunothai S, Zungsontiporn C. Cost of acute and sub-acute care for stroke patients. J Med Assoc Thai. 2012 Oct;95(10):1266-77.

25. Nor Azlin MN, Syed Aljunid SJ, Noor Azahz A, Amrizal MN, Saperi S. Direct medical cost of stroke: findings from a tertiary hospital in malaysia. Med J Malaysia. 2012 Oct;67(5):473-7.

26. Khealani BA, Javed ZF, Syed NA, Shafqat S, Wasay M. Cost of acute stroke care at a tertiary care hospital in Karachi, Pakistan. J Pak Med Assoc. 2003 Nov;53(11):552-5.

27. Grieve R, Hutton J, Bhalla A, Rastenytë D, Ryglewicz D, Sarti C, et al. A comparison of the costs and survival of hospital-admitted stroke patients across Europe. Stroke. 2001 Jul;32(7):1684-91. https://doi.org/10.1161/01.STR.32.7.1684

28. Christensen MC, Previgliano I, Capparelli FJ, Lerman D, Lee WC, Wainsztein NA. Acute treatment costs of intracerebral hemorrhage and ischemic stroke in Argentina. Acta Neurol Scand. 2009 Apr;119(4):246-53.https://doi.org/10.1111/j.1600-0404.2008.01094.x

29. Brinjikji W, Rabinstein AA, Cloft HJ. Hospitalization costs for acute ischemic stroke patients treated with intravenous thrombolysis in the United States are substantially higher than medicare payments. Stroke. 2012 Apr;43(4):1131-3. https://doi.org/10.1161/STROKEAHA.111.636142

30. Rai AT, Boo S, Buseman C, Adcock AK, Tarabishy AR, Miller MM, et al. Intravenous thrombolysis before endovascular therapy for large vessel strokes can lead to significantly higher hospital costs without improving outcomes. J Neurointerv Surg. 2018 Jan;10(1):17-21. https://doi.org/10.1136/neurintsurg-2016-012830

31. Specogna AV, Turin TC, Patten SB, Hill MD. Hospital treatment costs and length of stay associated with hypertension and multimorbidity after hemorrhagic stroke. BMC Neurol. 2017 Aug;17(1):158. https://doi.org/10.1186/s12883-017-0930-2
32. Dodel R, Winter Y, Ringel F, Spottke A, Gharevi N, Müller I, et al. Cost of illness in subarachnoid hemorrhage: a German longitudinal study. Stroke. 2010 Dec;41(12):2918-23. https://doi.org/10.1161/STROKEAHA.110.586826

33. Yundt KD, Dacey RG Jr, Diringer MN. Hospital resource utilization in the treatment of cerebral aneurysms. J Neurosurg. 1996 Sep;85(3):403-9. https://doi.org/10.3171/jns.1996.85.3.0403

34. Venketasubramanian N, Yin A. Hospital costs for stroke care in Singapore. Cerebrovasc Dis. 2000 Jul-Aug;10(4):320-6. https://doi.org/10.1159/000016077

35. Bairstow P, Dodgson A, Linto J, Khangure M. Comparison of cost and outcome of endovascular and neurosurgical procedures in the treatment of ruptured intracranial aneurysms. Australas Radiol. 2002 Sep;46(3):249-51. https://doi.org/10.1046/j.1440-1673.2002.01053.x

36. Brinjikji W, Kallmes DF, Lanzino G, Cloft HJ. Hospitalization costs for endovascular and surgical treatment of ruptured aneurysms in the United States are substantially higher than Medicare payments. AJNR Am J Neuroradiol. 2012 Jun;33(6):1037-40. https://doi.org/10.3174/ajnr.A2938

37. Buisman LR, Tan SS, Nederkoorn PJ, Koudstaal PJ, Redekop WK. Hospital costs of ischemic stroke and TIA in the Netherlands. Neurology. 2015 Jun;84(22):2208-15. https://doi.org/10.1212/WNL.0000000000001635

38. Chandratheva A, Geraghty OC, Luengo-Fernandez R, Rothwell PM; Oxford Vascular Study. ABCD2 score predicts severity rather than risk of early recurrent events after transient ischemic attack. Stroke. 2010 May;41(5):851-6. https://doi.org/10.1161/STROKEAHA.109.570010

39. Beuren IM, Schlindwein NF. Uso do Custeio por Absorção e do Sistema RKW para gerar informações gerenciais: um estudo de caso em hospital. AB Custos. 2008;3(2):24-47. 